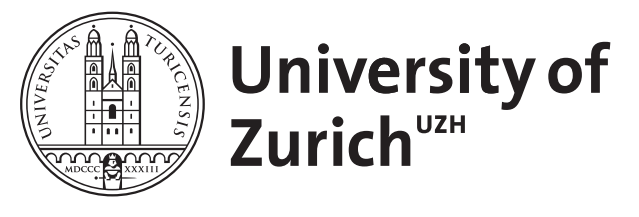

\title{
Methods for assessment of dental erosion
}

Attin, Thomas ; Wegehaupt, Florian Just

\begin{abstract}
Various assessment techniques have been applied to evaluate the loss of dental hard tissue and the surface-softened zone in enamel induced by erosive challenges. In this chapter, the most frequently adopted techniques for analyzing the erosively altered dental hard tissues are reviewed, such as profilometry, measuring microscope techniques, microradiography, scanning electron microscopy, atom force microscopy, nano- and microhardness tests and iodide permeability test. Moreover, methods for chemical analysis of minerals dissolved from dental hard tissue are discussed. It becomes evident that the complex nature of erosive mineral loss and dissolution might not be comprehended by a single technique, but needs application of different approaches for full understanding.
\end{abstract}

DOI: https://doi.org/10.1159/000360355

Posted at the Zurich Open Repository and Archive, University of Zurich

ZORA URL: https://doi.org/10.5167/uzh-106209

Book Section

Published Version

Originally published at:

Attin, Thomas; Wegehaupt, Florian Just (2014). Methods for assessment of dental erosion. In: Lussi, A; Ganss, C. Erosive Tooth Wear (From Diagnosis to Therapy). Basel: Karger, 123-142.

DOI: https://doi.org/10.1159/000360355 


\title{
Methods for Assessment of Dental Erosion
}

\author{
Thomas Attin, Florian Just Wegehaupt \\ Center for Dental Medicine, \\ Clinic for Preventive Dentistry, Periodontology and Cariology, \\ University of Zurich, Zürich, Switzerland
}

\begin{abstract}
Various assessment techniques have been applied to evaluate the loss of dental hard tissue and the surface-softened zone in enamel induced by erosive challenges. In this chapter, the most frequently adopted techniques for analyzing the erosively altered dental hard tissues are reviewed, such as profilometry, microradiography, scanning electron microscopy, atom force microscopy, nano- and microhardness tests and iodide permeability test. Moreover, methods for chemical analysis of minerals dissolved from dental hard tissue are discussed. It becomes evident that the complex nature of erosive mineral loss and dissolution might not be comprehended by a single technique, but needs application of different approaches for full understanding.
\end{abstract}

Copyright $\odot 2006$ S. Karger AG, Basel

Acid attack leads to an irreversible loss of the outermost enamel and dentin layers and to partial demineralization (softening) of the tooth surface. In enamel, the thickness of the softened layer is estimated to be $2-5 \mathrm{Um} \mathrm{[1,2]} \mathrm{[1,}$ 2]. The softened eroded tooth surface is highly susceptible to abrasive wear, and mechanical impacts such as toothbrushing can easily remove the superficially demineralized dental hard tissue [3-5] [3-5].

For simulating intra-oral erosion as closely as possible, it is desirable to assess the erosive effects on native tooth surfaces. Most of the methods described below need polished surfaces for precise assessment of the erosively induced defects or for creating reference surfaces, which means that the natural, often fluoridated surface of the tooth has to be removed. However, it should be considered that in the case of intra-oral erosion the outermost surface layers are also continuously removed by the acid attack, so that a 'polished' surface is 
cre- ated. When monitoring of erosive surface alterations within a period of time is performed, it could become necessary to fix a specimen in the measuring device in a reproducible position. This aspect becomes increasingly more important the smaller the mineral loss is.

In the oral cavity, the contact of the teeth with an acidic substrate is usually limited to a few seconds before clearance by saliva. This means that under natural conditions an early erosive lesion is created with very small loss of mineral and erosive craters in a nanometer scale or even a nearatomic level. Detection of these small surface changes would allow reducing the contact of an acidic substrate with the tooth surface in experiments to a time period resembling intra-oral conditions. Moreover, feasibility to detect these small alterations would enable one to reduce contact of the substrate with a tooth to a single and short event instead of long or repeated procedures which are dis- advantageous in in situ and in vitro experiments. When erosion is assessed in dentin specimens, it is important to notice that drying of a dentin may lead to shrinkage of the specimen rendering the detection of small surface alterations and loss diff icult.

It has, however, to be noted that assessment procedures should fulfill intraassay (coefficient of variation of $<10 \%$ ) and inter-assay precision with time (coefficient of variation of $<20 \%$ ) according to the guidance for bioanalytical methods as recently described $[6,7][6,7]$. Moreover, lower limits of quantification should be determined before application of a method meaning that only those readings should be considered in the analysis that are higher than the value of detection limit plus $5 \mathbf{X}$ SD [6,7] $[6,7]$. The limit of detection and the precision of a method may depend on the substrate to be analyzed, so that these parameters could not be taken from manufacturers' descriptions, since exemplarily shown for a calcium assay [8] [8]. Unfortunately, only in few erosion studies are these parameters clearly given for the specific assessment methods applied. Generally, qualitative assessments bear the problem that classification and interpretation of the findings is more or less subjective depending on the inves- tigator. In order to get objective and measurable data, quantitative analyses should be preferred when possible. However, with qualitative determinations [such as SEM and confocal laser scanning microscopy (CLSM)] changes of tooth structure could be visualized giving an impression to the reader of the different impacts of different substrates on the dental hard tissues.

Due to the lack of fixed intra-oral reference points, it is complicated to monitor the progression of erosive tooth wear accurately on natural tooth sur- faces in the oral cavity. Moreover, most of the devices used for detection of mineral loss and changes could only be performed on 
especially prepared spec- imens. Therefore, erosive and erosive/abrasive alterations of dental hard tissues are mostly investigated either in in vitro studies or in in situ studies. In the latter ones, enamel or dentin specimens are extra-orally or sometimes intra-orally subjected to erosive challenges, worn in the oral cavity according to the intra- oral cariogenicity test developed by [9-11] [9-11] and finally assessed in the labora- tory for hard tissue loss and surface alterations.

Due to the two patterns - loss and softening of the dental hard tissue assessments of dental erosions deal with different methodological approaches, namely to evaluate either surface phenomena only, such as change of surface hardness, or the loss of the dental hard tissues per se. Various techniques have been used to investigate these two aspects of dental erosion [12] [13] [12, 13].

In the following, the most established and well-evaluated techniques as well as emerging methods will be described.

\section{Scanning Electron Microscopy}

With scanning electron microscopy (SEM) surface alterations after erosive attacks are qualitatively estimated in some studies [14] [15]. Grading of the severity of surface alteration could be done on individually adopted scales. SEM investigations can be per- formed on both polished and unpolished, native surfaces after gold-sputtering. In enamel, acid attacks due to immersion of specimens in erosive solutions lead to a surface etching pattern with exposition of enamel prisms to an extent depending on the severity of the erosive challenge. SEM investigations were also applied for evaluating the efficacy of salivary acquired pellicle to protect underlying enamel surface from acidic dissolution [16-18] [14-16] or to demonstrate superficially deposited precipitates resulting from mineral dissolution with dif- ferently acting acids [19] [17]. In dentin, acid treatments may result in opening of the dentin tubules which could be graded according to its degree [20] [18]. With common scanning electron microscopes, moisture loss of specimens due to necessary preparation of the specimens for the SEM investigation may lead to additional alterations of the eroded surface. To avoid collapse of the fragile eroded enamel surface structure, freeze drying of samples was suggested [21] [19]. Precipitates formed by dissolved enamel mineral may block the enamel surface so that the eroded enamel prism structure might not be seen with SEM. To reduce the risk of artefactual reprecipitation, neutralization of the acid is rec- ommended before removal of samples from the acidic bath. Impregnation of the delicate surface with methacrylate or dentin adhesives allows for fabrication of resin replicas [22] [20]. After 
complete dissolution of the enamel with $\mathrm{HCl}$, the resin replicas could then be studied with SEM providing insight into structural sur- face and subsurface changes.

With environmental SEM (ESEM), no sample preparation is required, reducing the risk for artefacts to a minimum. ESEM also allows for examination of samples without metal or carbon coating, respectively, in low vacuum

and in wet conditions. Nevertheless, SEM and ESEM technique does not pro- vide as detailed information about surface alterations of eroded samples as other methods used for the evaluation of erosive impact on dental hard tissues.

SEM or ESEM could be coupled with energy dispersive X-ray spectroscopy and was also used for a microanalysis suitable for analyzing elemental distribution in the top few micrometers of a sample surface. An electron beam hitting the surface leads to excitement of atoms resulting in emitting of X-rays which may provide information about distribution of various elements, such as calcium, phosphate and carbon with a concentration of about $1 \mathrm{wt} \%$. However, suitability of the method for evaluating erosive processes has not been clearly demonstrated as yet [23] [21].

Both SEM and ESEM are suitable for use with native surfaces. Although, both methods do only allow subjective, qualitative assessment. ESEM is favor- able when wet substrates or dentin should be evaluated.

\section{Surface Hardness Measurements}

For determining changes of surface hardness of erosively altered dental hard tissues, microhardness and, as a relatively new approach, nanoindentation techniques are often used. With hardness measurements, early stages of enamel and dentin dissolution, which are associated with weakening of the surface, can be determined. The basic method of microand nanoindentation involves the indentation of a diamond tip of known geometrical dimensions for a given load and duration.

For microhardness assessments of eroded tooth surfaces, mostly the diamonds according to Knoop or Vickers used on previously polished surfaces. Polished surfaces are recommended to produce well-defined indentations. Application of Knoop diamond resulted in a rhomboid indentation, Vickers in a tetra-pyramidal one. The lengths of the indentations on the surface are mea- sured under a microscope requiring indentations lengths of about 30-40 $\mathrm{Um}$ length for precise measurements. By means of a special formula Knoop or Vickers hardness numbers are 
calculated. In enamel, length of the indentations is not time-dependent and could be recorded immediately. However, in dentin, indentation length changed due to flexibility of the dentin substrate, which was shown for indentations performed with $500 \mathrm{~g}$. In this case, indentations should best be measured $24 \mathrm{~h}$ after having made the indentation [24] [22]. No comparable recommendations are available for dentin indentations conducted with lower forces, although it could be assumed that when applying low forces the time needed to retraction of dentin after loading might be shorter than $24 \mathrm{~h}$. On erosively altered surfaces, the outlines of the indentations are sometimes fuzzy rendering precise measurements difficult. The hardness measured by indenta- tion is affected not only by the immediate surrounding, but also by changes of the material in a distance of approximately 10 times the dimensions of the indentation. To limit the impact of surrounding material changes, microindenta- tions for determining erosive alterations of the superficial surfaces are per- formed with low pressure of about $50 \mathrm{~g}(0.49 \mathrm{~N})[25,26][23,24]$. Nevertheless, one should be aware that microhardness measurements do not reflect the properties of the surface only. The penetration depth of the Vickers diamond amounted to $1 / 7$ of indentation length; i.e. with indentations from, e.g., $35 \mathrm{Um}$ length, the depth of penetration amounts to $5.0 \mathrm{Um}$. Penetration depth of the Knoop dia- mond amounts to $1 / 30.5$ of its indentation length. This means that with same indentation length and visibility under the assessment microscope the Knoop hardness determination better reflects alterations of the actually outermost lay- ers than the Vickers hardness testing, since Knoop hardness indentations from,

e.g., $35 \mathrm{Um}$ length are equivalent to a penetration depth of $1.15 \mathrm{Um}$. Nevertheless, microhardness measurements such as the Knoop procedure allow discriminating different erosive potentials of various substances on dental hard tissue, even after short exposures ( $3 \mathrm{~min}$ ) to acidic agents [27] [25]. In other studies, immersion periods of at least $20 \mathrm{~min}$ were chosen to investigate the impact on surface hard- ness [28] [29] [30] [23, 26, 27].

By means of the indentations on enamel surfaces detection of enamel abrasion is also possible by calculating the depth of the indentations. The difference between the depth before and the depth after abrasion provided a direct measurement for the loss of substance by abrasion at this site [31,32] [33] [34] $[28,29]$. The main principle behind this method is that the body of the indentation is not changed and not removed by the abrasion. Only the surrounding tissue on the surface is removed so that due to the pyramidal geometry the contour of the indentation (an thereby its length) is reduced $[31,32] \quad[28,29]$. The substance loss $(\Delta d)$ is calculated from the change in indentation length $(\Delta \mathrm{l})$ using the geometrical formula:

$\Delta \mathrm{d}=0.032772 \Delta \mathrm{l}$. With this procedure, surface loss due to abrasion 
of previ- ously eroded samples of about $30-100 \mathrm{~nm}$ could be determined precisely $[35,36][30,31]$. Unfortunately, measurements of the amount of substance directly removed by an erosive attack could not be performed with this method, since the acid also removes some substance from the body of the indentation and not only from its surrounding.

In another approach, Schweizer-Hirt et al. [37] [32] visually compared different degrees of disappearance of the indentations after enamel erosionabrasion, thus estimating substance loss.

The main advantages of microhardness determinations are the relatively low costs, the long experience with the system and the fact that it could be combined with measurements of abrasive surface loss.

\section{Surface Profilometry}

Using a surface profilometer (surfometer) irreversible loss of dental hard tissue and surface roughness could be determined by scanning specimens with a laser beam or a contact stylus (metal or diamond) with a diameter of about 2-20 $\mathrm{Jm}[4,38,39]$ [40,41] [42] [43] [44-46] [47,48] [49] [4, 33-36]. The contact stylus is loaded with a force of a few milli- Newtons. With the scan, a complete map of the specimen surface could be generated. However, the outermost demineralized layer of enamel erosions is very damageable to mechanical forces so that profilometer measurements will be effected by the tendency of the stylus to penetrate this fragile layer. The tip of the stylus could also be used to render scratches on eroded and noneroded surfaces. By means of atomic force micrsocopy the depth of the scratch could be quantitatively measured to a nanometer scale in the range of about $10 \mathrm{~nm}[50,51]$.

Application of the laser beam leads to higher resolution as compared to the contact stylus (resolution on accuracy in height $>10 \mathrm{~nm}$ ). However, the laser stylus may produce 'overshots' at the sharp edges at the bottom of grooves which result in artefacts [52] [37]. It should also be noted that dissolution of the enamel due to acid attack leads to surface roughening of about $0.4 \mathrm{Jm}$.

Therefore, reliable detection of minimal losses below $1 \mathrm{Jm}$ are generally difficult to accomplish with profilometry, although Hooper et al. [53] [38] have demonstrated that profilom- etry was able to distinguish between different abrasivities of toothpastes creating hard tissue loss of about $0.5 \mathrm{Jm}$. For such precise measurements with low varia- tions, meticulous flattening and polishing of sample surface is an important step.

In studies using surfometry, parts of the surface are protected by nail varnish or adhesive tape prior to the erosive or abrasive attack to produce reference areas allowing comparison between the levels of the untreated and treated sur- faces. However, it is also possible to match the baseline 
scan recorded with the scan conducted after treatment in a computer in order to determine differences in height between these two scans with a special software[54] [55] [39, 40]. In this case, it is extremely important to ensure correct repositioning of the sample in the profilometer for the two readings.

When measuring eroded dentin surfaces it has to be respected that dentin and especially eroded dentin is shrinking under ambient conditions. Thus it was recommended to apply surface profilonetry using dentin samples under wet conditions [56]. Moreover, it should be noticed that surface profilometry of eroded dentin might interfere with the exposed collagene matrix, thus not reflecting mineral loss of the bulk dentin specimen adequately [57].

Commonly, polished surfaces are used in profilometry studies, since native enamel or dentin surface show an intrinsic coarseness rendering detection of small changes due to erosion/abrasion impossible. However, in natural enamel extended depths of at least $50 \mathrm{~lm}$ of erosive grooves could also be measured without the need for preparation (polishing) of the surface [39] [34].

Chadwick et al. [58] [41] presented a method to obtain digital surface models using electroconductive replicas generated from silicone impressions of teeth taken at different time points. The replicas were used for surface mapping, by means of a computer-controlled probe. Resolution in z-direction is reported to be $1 \mathrm{Um} \mathrm{[59]} \mathrm{[42].} \mathrm{The} \mathrm{resultant} \mathrm{maps} \mathrm{may} \mathrm{be}$ compared using a surface matching and difference detection algorithm. This technique provides readings with good accuracy and reproducibility [60-62] [43-45]. Erosions of $50 \mathrm{Um}$ magnitude occurring over a 9 month period were recorded to a precision of about $\pm 15 \mathrm{Um}$ [59] [42].

As summarized, profilometry is a method, which may be adopted for surface loss with high precision provided that material loss exceeds about 0.4 $\mathrm{Um}$. The method is also applicable for indirect measurements of intra-oral erosions via replicas.

\section{Iodide Permeability Test}

Iodide permeability tests (IPT) were introduced by Bakhos et al. [63] [46] and is based on the principle that defined areas of enamel samples are allowed to soak for a few minutes with potassium iodide which is recovered from the enamel by Millipore prefilter paper discs. The amount of iodide recovered in the discs is determined and provides information about the pore volume of the enamel. It was shown that (IPT) measurements are closely related to the pore 
volume of enamel and give sensitive estimations of the early stages of de- and remineralization [64] [47]. Moreover, it was proven that a linear relationship between IP and calcium loss exists [65] [48]. Changes of enamel structure recorded with IPT have also been shown to correlate well with microhardness testing. This was true for severely eroded samples, in which erosions were performed by immersion in lactate $(\mathrm{pH} \mathrm{4.75)}$ ) for a minimum of $60 \mathrm{~min}$ [66] [49]. With shorter exposure periods in the erosive solution, the two methods did not correlate well in this study. Lussi et al. [28] [26] showed that exposure to acidic drinks leads to an increase in IP which was significantly associated with the acidity, $\mathrm{pH}$, and min- eral contents of the drinks. In contrast to the aforementioned study, Lussi et al. [28] [26] found a correlation between IP and microhardness data for enamel samples immersed in acidic beverages for a period of $20 \mathrm{~min}$.

The IP method has the advantage that low costs are involved with this approach, which allows more or less rapid screening of the impact of different erosive substances on enamel.

\section{Chemical Analysis of Minerals Dissolved in the Erosive Agent}

Dental enamel consists of $34-39 \% \mathrm{~m} / \mathrm{m}$ (g per $100 \mathrm{~g}$ ) calcium (dry weight) and $16-18 \% \mathrm{~m} / \mathrm{m}$ phosphorus [67] [50]. Therefore, determination of dental enamel dissolution by assessing the amount of calcium or phosphate dissolved from the apatite crystals of dental hard tissue could also be regarded as a possible tool for assessing dental erosions. Hence, some authors had applied calcium determina- tion in erosive, acidic solutions after prolonged contact (range $2 \mathrm{~min}$ to $24 \mathrm{~h}$ ) of the solutions with dental hard tissue using calcium sensitive electrodes, atomic adsorption spectrophotometer or the highly sensitive method of inductively coupled plasma mass spectrometry [68-72] $[73,74][75,76][51-55]$.

\section{Calcium-sensitive electrodes}

often need a specific $\mathrm{pH}$ of the environment to work precisely. Additionally, cal- cium complexes formed with certain acids (e.g. citric acid) impair correct mea- surements of the calcium released from the dental hard tissue. Atomic absorption spectrophotometer requires intensive preparation of the solution to allow for measurement of calcium or phosphate. Both methods additionally need solution volumes exceeding a minimum of

$100 \mathrm{vl}$. Atomic absorption spectrophotometer uses the adsorption of light, usually from a hollow-cathode lamp of the element that is being measured, to determine the concentration of gas-phase atoms. Since samples are usually liquids or solids, the analyte atoms or ions must be vaporized in a 
flame or graphite furnace. The atoms absorb ultraviolet or visible light and make transitions to higher electronic energy lev- els. The analyte concentration is determined from the amount of absorption. Concentration measurements are usually determined from a working curve after calibrating the instrument with standards of known concentration. With the inductively coupled plasma mas spectrometry, the ions are ionized by inductively coupled plasma and quantified by a mass spectrometer. The method is highly sensitive, but susceptible to contamination.

Recently, the colorimetric Arsenazo III method was described allowing precise determination in acidic solution of small volumes of $10 \mathrm{Ul}$ in a spectropho- tometer [8] [19] [8, 17]. However, this method also could not be applied in all kind of acids with the same precision. In colorimetric methods, absorbance of light due to the formed colored complex is related to the quantity of the analyte. It should be noted that formation of the colored complex might be impaired by other agents in the solution or by $\mathrm{pH}$.

Determination of phosphorus released during the dissolution process is mostly performed by colorimetric methods such as the ammonium(phospho-) molybdate method [77,78] [56, 57]. Another colorimetric method, with a 10 times higher sensitivity, is the phosphomolybdatemalachite green procedure [79] [58] which has shown to be suitable for determination of phosphate dissolved from enamel after etching with perchloric acid at a range of 0.025-3.0 $\mathrm{mM}$ [80][59]. Recent studies corroborated this fact showing that, depending on the acid used, the malachite green procedure is a reliable and suitable tool to detect and quantify minimal phosphate contents in small samples of a variety of acidic solu- tions which have the potential to form erosive lesions [81] [60].

The chemical methods for assessment of erosive dissolution have the advantage that they allow detection of very small mineral loss using unpolished, native tooth samples. As yet, these methods were only applied in in vitro exper- iments.

\section{Microradiography}

Microradiography is a tool for quantification of mineral loss based on the attenuation of X-ray irradiation transmitting dental hard tissue. X-ray photons transmitting a dental hard tissue sample can be recorded by photocounting X- ray detectors, or X-ray sensitive photographic plates or film. The mineral mass can be calculated from the photon counts or gray values of photographic plates or film knowing the appropriate mass attenuation coefficient or by determining photographic density measurements 
calibrated by an aluminum step-wedge [82-84] [61-63]. For gray value assessment of photographic plates or film densitome- ters or, more recently, CCD cameras attached to a microscope are in use.

Microradiography has been frequently used in studies determining mineral changes due to de- and remineralization in terms of caries. The method was used for studying these processes in early enamel lesions and less frequently in dentin. For transverse microradiography (TMR) thin sections (50-200 $\mathrm{Im}$ ) are obtained perpendicular to the sample surface and radiographed with a Nickel- filtered $\mathrm{Cu} \mathrm{Ka-line} \mathrm{(i.e.} \mathrm{at} 20 \mathrm{kV}, 20 \mathrm{~mA}$ ) perpendicular to the cut surface. Due to limitations in specimen preparation and alignment, and the geometry of the X-ray beam that spreads radial from a point or line focus rather than parallel, the imaging precision at the sample edge is limited. Usually, the outermost

$5-10 \mathrm{Um}$ cannot be exactly reproduced. In early enamel caries with the typical subsurface lesion, mineral loss and changes predominantly occur in the body of the lesion below the pseudo-intact surface layer at about $20-50 \mathrm{Um}$ thickness and beyond [85] [64]. TMR is a valid tool for quantitative assessment of the mineral content as a function of depth from the surface of caries and caries-like lesions. From in-depth profiles, the lesion depth and mineral loss integrated over the entire depth (IML or $\Delta \mathrm{Z}$ ) of the lesion can be calculated. Lesion depth usually is defined up to that point, where the mineral content reaches $95 \%$ of the min- eral content of sound enamel or dentin.

Beyond its original use in caries research, microradiography was adopted for detecting erosive mineral loss. In a TMR-like setup thin enamel or dentin sections can be used to measure erosive mineral loss. In this case, the erosive agent is applied on the cut surface that also contains reference areas not subjected to erosion and X-ray images are taken [86] [65]. Note that in contrast to TMR, as is usually applied in caries research, the erosion is performed on the cut sur- face of an already prepared tooth slice of 100-200 Um thickness rather than on a specimen's surface that is cut perpendicularly for TMR after an experimental procedure. Hall et al. [86] [65] found a strong correlation between mineral loss determined by either TMR or profilometry even for discrimination of early ero- sive lesions caused by erosion times of less than 1 h.

Another approach to use TMR for erosive mineral loss determination also depends on the use of reference areas not subjected to an erosive challenge [87] [88] [66]. The erosive challenge is executed on a specimens' surface. Then a slice $(50-200 \mathrm{Um})$ is prepared perpendicular to the surface the same way as for tradi- tional TMR. Thereby, both depth of the erosive crater and the depth below the bottom of the crater at which mineral content was reduced (surface softening) can be assessed with TMR giving lesion depth and integrated 
mineral loss as variables $[89,90][42][67,68]$. In these studies, TMR was used to record lesion depths from

$20 \mathrm{Um}$ and more. For determination of mineral changes following a small ero- sive challenge, e.g. erosive surface softening only, this technique is not sensitive enough due to the fuzziness of the outer 5-10 $\mathrm{lm}$ at the edge of the dental hard tissue slabs prepared for TMR.

Longitudinal microradiography (LMR) enables the use of thicker specimens up to $4 \mathrm{~mm}$ thickness usually cut from the tooth comprising the natural enamel surface and some underlying dentin. However, use of thinner specimens provides better information about the mineral change within the specimen. The specimens are radiographed perpendicular to the surface before (reference) and after treatment(s), and changes in mineral content can be calculated using pixel by pixel comparison of gray values of a radiograph after treatment with the gray values of the reference radiograph. In contrast to TMR, LMR is not able to determine the mineral profile of a specimen from the surface to depth. Since LMR enables the reuse of specimens, it can be used for longitudinal observations. The mineral loss recorded with LMR consists of both the erosive crater and the loss of mineral in the softened surface zone. LMR is less sensitive to minute changes in mineral content than TMR, because of the use of thicker specimens as compared with TMR.

Using LMR, erosion progression in both enamel and dentin has also been assessed [91-93] [69-71]. In these studies, the method has shown to be suitable to allow for distinction of different preventive treatment modalities resulting in different mineral loss. Comparison of LMR in enamel specimens with either profilometry, analysis of dissolved calcium/phosphorus and nanoindentation measurements showed good correlation for the three methods [94,95] [72]. However, it also became clear that losses below $20 \mathrm{Um}$ should be interpreted with care when using LMR only, since standard deviations were quite high when determining minimal substance loss with LMR.

The main advantage of microradiography is that the method enables to simultaneously determine surface loss and demineralization of the eroded samples.

\section{Confocal Laser Scanning Microscopy}

CLSM is a tool for obtaining high-resolution images, 3-D reconstructions and optical sections through 3-D specimens. The translucency of teeth allows nondestructive subsurface visualization of their microstructure by

CLSM used in reflection mode at a level of about 150-200 $\mathrm{Um}$ below the surface [96-98] [73-75]. Although mostly polished tooth samples are used 
for CLSM, also unpolished

and even wet tooth substrates could be assessed with the method. However, quality of images obtained from unpolished samples is limited due to reflections and scattering effects caused by the uneven surface. Moreover, surfaces of polished samples could quite easily be aligned parallel to the ground which is required to obtain images from a defined subsurface level.

In brief, CLSM works as follows: illumination, provided by a gas laser (e.g. $\mathrm{Ar} / \mathrm{Kr}$ or $\mathrm{He} / \mathrm{Ar}$ ) is focused by an objective lens into a small focal volume within a fluorescent specimen. The laser beam, which could be filtered to select specific wavelengths (often $488 \mathrm{~nm}$ ) is thereby focused on the focal plane. A mixture of emitted fluorescent light as well as reflected laser light from the illu- minated spot is then recollected by the objective lenses and a photon multiplier detector. The focus plane of illumination is the same as the focal plane of detec- tion, which means that they are confocal. Information of the specimen can be collected from different focal planes by raising or lowering the microscopes stage. The computer can generate a 3-D picture of a sample by assembling a stack of these 2-D images from successive focal planes.

Used in erosion studies, CLSM provides histotomographic images allow- ing for qualitative assessment and interpretation of hard tissue destruction or mineral dissolution, since light reflection and light scattering of hard tissue samples are influenced by micro-histological changes within a tooth sample[99-101] [76-78]. Since these images provide only limited information about the exact degree of demineralization, CLSM is mostly combined with other methods (e.g. microhardness, analysis of mineral loss or others). Recently, CLSM war applied also to sections of erosive lesion to measure depth of erosive loss and of demineralization [102]. This procedure, however, needs some further validation.

The main advantage of CLSM is the high resolution of the system provid- ing a 3-D insight into the erosively altered substrate.

\section{Quantitative Light-Induced Fluorescence}

Quantitative light-induced fluorescence (QLF) was developed as a nondestructive diagnostic method for the longitudinal assessment of early caries lesions [103] [79]. The method applies a xenon gas discharge lamp to illuminate a tooth with filtered blue-violet light to provoke its natural fluorescence. The nat- ural fluorescence is assumed to be caused by fluorophores, which are predomi- nately located at the dentin-enamel junction and in dentin. Due to higher scattering in carious enamel less excitation light reaches the fluorescing dentin-enamel junction and 
underlying dentin and less fluorescence from the dentin-enamel junction and dentin is able to find its way back through the cari- ous lesion. Therefore, the lesion appears dark in contrast to the surrounding, fluorescing area of the tooth. The area of interest is imaged by a CCD video camera through an optical high-pass filter that blocks the excitation light and allows only the fluorescing light to pass. The averaged difference in fluores- cence intensity

( $\mathrm{F}$ [\%]) between the darker fluorescing lesion area and the brighter fluorescing sound area around the lesion is calculated by proprietary software. As yet, QLF was applied in only few studies for monitoring erosive lesions [104,105] [106] [80,81]. The method was validated in comparison to TMR and was found to be an effective tool for quantification of erosive defects. As already mentioned, the erosive lesion comprises a crater and a softened demineralized surface layer. It could be assumed that the softened surface layer is too thin to create scattering effects of light to such an extent as observed in carious lesions, so that the dem- ineralized surface layer could not account for the loss of fluorescence of the erosive lesion. Therefore, it was hypothesized that the walls of the crater of the erosion are primarily responsible for the dark appearance of the lesion when assessed with QLF. It was assumed that the walls create a shadowing effect and that they hinder release of the fluorescing light due to scattering. With an increase of the depth of the crater, these effects might also increase leading to a more pronounced accentuation of the erosive defect when assessed with QLF. However, the principle behind the reduced fluorescence of erosive lesions is not fully understood and needs to be clarified in further experiments.

\section{Atomic Force Microscopy}

Atomic force microscopes (AFM) as well as scanning tunneling microscopes are pertaining to the family of scanning probe microscopes. In the fol- lowing, some properties of the instrument are given as already described in detail elsewhere $[13,23,107][13,21,82]$. The main application of AFM is high resolution imaging of different materials including polymers, ceramics, metals, biomole- cules and cells. Different operation modes allow measurement of among others surface topography, lateral surface composition and differences in elasticity. Ultra-sharp probes with radii of 4-60 $\mathrm{nm}$ are connected to a flexible cantilever and accurate ceramic piezo-elements, which allow the sample to be scanned with subnanometer precision. The cantilever deflects in the z-direction due to the surface topography during tip scanning over the surface. A diode laser beam is reflected from the back of the cantilever and is incident on a four- 
segment photodiode. As the tip moves, the deflection of the cantilever is indicated by the position of the laser on the photodiode, thus constructing a map of the sample surface [23] [21]. The tip can move over the sample in dynamic modes with an oscil- lating tip moving up and down in either tapping mode (with touching surface contacts) or noncontact mode. In noncontact modes, the tip is placed at the level of the attractive van der Waals forces to detect force gradients. In nondynamic modes, the tip is moved laterally in constant contact with the surface (contact mode). AFM can be used equally well on conducting and insulating materials in ambient conditions, in air or liquids. The resolution is orders of magnitude greater than with profilometry, however, scan size is limited to at most

\section{$0.5 \mathbf{X}$}

$0.5 \mathrm{~mm}^{2}$ taking some $60 \mathrm{~min}$ for this

size.

AFM was used in erosion studies for qualitative approaches comparing the surface of dental hard tissue and acquired enamel pellicle after exposure to dif- ferent erosive agents [108-110] [83-85]. Moreover, substance loss of enamel due to ero- sion was determined with tapping mode [109] [84] with high resolution. Generally, AFM is able to measure height differences in the order of the size of one atom rendering the technique suitable for detection of very early stages of substance loss due to erosive and abrasive attacks. AFM is also suitable to produce images of erosively altered surfaces of dental hard tissues or to measure surface roughness [111,112].

\section{Nanoindentation}

For nanoindentation, an indenter diamond is applied on dental hard tissue with small loads in the order of $\mathrm{nN}$ to $\mathrm{mN}$. Therefore, the indentation depth of the indenter tip could be limited to about $100 \mathrm{~nm}$ allowing for measurements in the outermost softened layer. Mostly, a Berkovich diamond tip is used resulting in a three-sided pyramidal indentation. The indenter is driven into the sample by applying increasing load to some preset value. The load is gradually decreased until partial or complete relaxation of the sample has occurred. The load and displacement are recorded continuously throughout this process to produce a load displacement curve form from which the nanomechanical properties such as Young's modulus of elasticity, hardness, fracture toughness, time-dependent creep and plastic and elastic energy of the sample could be calculated [113] [114] [86]. Elastic modulus data may be useful in studies of erosion, since it has been shown to be more sensitive than hardness to the presence of underlying hard material. Indentation depth at some 4,500 $\mathrm{UN}$ force in orange juice treated enamel was 
recorded to be in a range of about $200-500 \mathrm{~nm}$. In comparison, watertreated samples showed indentation depth of $150-350 \mathrm{~nm}$ [115] [87]. The nanoindenter could be coupled to the vertical transducer used in combination with AFM, where the cantilever and the laser-optical system is replaced by the transducer-tip system allowing for determination of tip displacements with $0.2 \mathrm{~nm}$ resolution [107] [116] [82]. The tip can be scanned across a sub- strate, building up an image of the area in contact with the tip. Due to the small size of the tip and the indentations with lengths of about

$2 \mathrm{Um}$, the method should be applicable on unpolished samples and for measurements in tiny, defined surface areas. The nanoindentation method is a very sensitive tool which is able to pro- vide information about material properties.

\section{Element Analysis of Solid Samples}

In vitro, trace element analysis of solid tooth samples is feasible with a variety of methods such as, secondary ion mass spectroscopy (SIMS), electron probe microanalysis, laser ablation inductively coupled plasma mass spectroscopy, micro X-ray fluorescence, proton-induced X-ray emission spec- troscopy and transmission electron microscopy coupled with a X-ray detection system (Analytical-TEM), laser ablation inductively coupled plasma mass spectroscopy. However, most of these methods are not described for analyzing dental substrates as yet, although they would offer quantitative analysis of ele- ments in very low concentrations in very confined areas of solid samples.

Barbour and Rees [23] [21] described application of SIMS on erosively altered enamel surfaces giving either topographic images or calcium or magnesium surface maps. These images were able to provide information of element loss of the demineralized enamel. The depth of the erosive crater could not be deter- mined with SIMS. Mass spectrometric methods for trace analysis of inorganic materials provide a very sensitive multielemental analysis with limits of detec- tion of low ng $\mathrm{g}^{-1}$ concentration range [117] [88]. A broad variety of mass spectro- metric methods are described in the literature[118] [89], such as SIMS which allows mono- and multielemental trace analysis on solid materials or thin layers. When solid surfaces are bombarded with ions, these ions penetrate into the solid to a certain depth as a function of their energy and mass and the nature and structure of the sample. The bombarded ions transfer their energy to atoms of the solid. Part of the energy of the primary atoms is returned to the surface of the solid and causes sputtering of neutral particles or secondary ions. With SIMS, the secondary ions mass is analyzed in a mass spectrometer where 
the ions are separated according to their mass-to-charge ratio giving information about local enrichment or depletion of chemical elements as compared to standard refer- ence materials. However, SIMS is only partially quantitative and actual concen- trations cannot be measured accurately.

Electron probe microanalysis is another method establishing the chemical composition of very small volumes of solid material which needs to be polished to a plane surface. The method involves bombarding a specimen with a focused high energy beam of electrons and analyzing the X-ray spectrum emitted from the sample. The X-rays are characteristic of the bombarded elements and allow determination of the quantitative composition of the test samples with wave- length dispersive spectrometers [119] [90]. With sectioned samples element analysis could be performed in subsurface areas with the electron beam hitting the sec- tioned surface perpendicular to the natural sample surface. Willershausen and SchulzDobrick [120] [91] applied this method for evaluating element distribution in sections of eroded enamel in a depth of 5 up to $50 \mathrm{Jm}$. Measurements within the first few micrometers depth of sectioned samples are difficult to perform due to fuzziness at the outermost surface region.

Compared to scanning electron microscopes or transmission electron microscopes equipped with an energy detection system, wavelength dispersive X-ray analyzers in electron probe microanalysis reveals a much higher spectral sensitivity and lower detection limits. Highest lateral resolution ( $=$ smallest excited volumes) can be reached with analytical TEM, but this method suffers from the impractical sample preparation of thin specimens and its semiquantitative results.

In summary, element analysis of solid samples allows very sensitive measurements of early mineral loss depending on the method used. However, suit- ability for erosion assessment has to be checked for most of these methods in the future.

\section{Ultrasonic Measurement of Enamel Thickness}

With ultrasonic pulse-echo measurements the time interval between the transmission of an ultrasound pulse on the enamel surface and the echo produced by the amelodentinal junction is determined. Using these data and the mean longitudinal sound velocity in enamel, the thickness of the enamel layer can be calculated. The method is nondestructive allowing in vitro as well as in vivo measurements. It shows good correlation between different opera- tors [121] [92]. However, enamel thickness changes of less than 0.33 $\mathrm{mm}$ could not be detected precisely with this method [122] [93] and 
ultrasonic measurements and histological readings of enamel thickness are only moderately correlated [123] [94].

In table 1, the main advantages and main problems encountered with the described methods are depicted. Moreover, the methods are judged with respect to the requirements, such as their suitability for early erosion or for use with native surfaces. It becomes evident that the complex nature of erosive mineral loss and dissolution might not be comprehended by a single technique, but needs application of different approaches for full understanding. Especially for determination of early erosion, methods with high resolution providing high accuracy might be helpful to gain more insight into the true nature of erosion development as occurring in the oral cavity.

Table 1. Survey of the methods described in detail in the text with respect to main advantages and problems as well as to suitability for use with early erosions (after few minutes of acidic challenge) and with native, nonpol- ished surface samples

\begin{tabular}{|c|c|c|c|c|}
\hline Method & Advantages & Problems & $\begin{array}{l}\text { Suitability for } \\
\text { early erosion }\end{array}$ & $\begin{array}{l}\text { Suitability for use } \\
\text { with native } \\
\text { surfaces }\end{array}$ \\
\hline \multicolumn{5}{|c|}{ Acknowledgements } \\
\hline $\begin{array}{l}\text { Surface hardness } \\
\text { measurements }\end{array}$ & 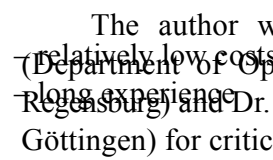 & 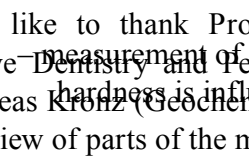 & $\begin{array}{l}\text { Wolfgang Buch } \\
\text { oloty+ University } \\
\text { stitute, Universit } \\
\text { pt. }\end{array}$ & $\begin{array}{l}\text { of a } \\
\text { of }\end{array}$ \\
\hline
\end{tabular}

\section{References}

1. Attin T, Buchalla W, Gollner M, Hellwig E: Use of variable remineralization periods to improve the abrasion resistance of previously eroded enamel. Caries Res 2000;34:48-52.

2. Eisenburger M, Hughes J, West NX, Jandt KD, Addy M: Ultrasonication as a method to study enamel demineralisation during acid erosion. Caries Res 2000;34:289-294.

3. Davis WB, Winter PJ: The effect of abrasion on enamel and 
dentine and exposure to dietary acid. Br Dent J 1980;148:253-256.

4. Attin T, Koidl U, Buchalla W, Schaller HG, Kielbassa AM, Hellwig E: Correlation of microhardness and wear in differently eroded bovine dental enamel. Arch Oral Biol 1997;42:243-250.

5. Smith BGN, Robb ND: Dental erosion in patients with chronicalcoholism. J Dent 1989;17:219-221.

6. Shah VP, Midha KK, Dighe S, McGilveray IJ, Skelly JP, Yacobi A, Layloff T, Viswanathan CT, Cook CE, McDowall RD: Analytical methods validation: bioavailability, bioequivalence and pharmacokinetic studies. Conference report. Eur J Drug Metab Pharmacokinet 1991;16:249-255.

7. Shah VP, Midha KK, Findlay JW, Hill HM, Hulse JD, McGilveray IJ, McKay G, Miller KJ, Patnaik RN, Powell ML, Tonelli A, Viswanathan CT, Yacobi A: Bioanalytical method validation--a revisit with a decade of progress. Pharm Res 2000;17:1551-1557.

8. Attin T, Becker K, Hannig C, Buchalla W, Hilgers R: Method to detect minimal amounts of calcium dissolved in acidic solutions. Caries Res 2005;39:432-436.

9. Koulourides T, Volker JF: Changes of enamal microhardness in the human mouth. Ala J Med Sci 1964;35:435-437.

10. Koulourides T, Phantumvanit P, Munksgaard EC, Housch T: An intraoral model used for studies of fluoride incorporation in enamel. J Oral Pathol 1974;3:185-196.

11. Koulourides T, Chien MC: The ICT in situ experimental model in dental research. J Dent Res 1992;71 Spec No:822-827.

12. Grenby TH: Methods of assessing erosion and erosive potential. Eur J Oral Sci 1996;104:207-214.

13. West NX, Jandt KD 2000. Methodologies and instrumentation to 
measure tooth wear; future perspectives. In Tooth wear and sensitivity, eds. Addy M, Embery G, Edgar WM, Orchadson R, pp. 105-120. London: Martin Dunitz

14. Magalhaes AC, Romanelli AC, Rios D, Comar LP, Navarro RS, Grizzo LT, Aranha AC, Buzalaf MA: Effect of a single application of TiF4 and $\mathrm{NaF}$ varnishes and solutions combined with $\mathrm{Nd}$ :YAG laser irradiation on enamel erosion in vitro. Photomed Laser Surg 2011;29:537-544.

15. Torres CP, Chinelatti MA, Gomes-Silva JM, Rizoli FA, Oliveira MA, Palma-Dibb RG, Borsatto MC: Surface and subsurface erosion of primary enamel by acid beverages over time. Braz Dent J 2010;21:337-345.

16. Meurman JH, Frank RM: Scanning electron microscopic study of the effect of salivary pellicle on enamel erosion. Caries Res 1991;25:1-6.

17. Hannig M, Balz M: Influence of in vivo formed salivary pellicle on enamel erosion. Caries Res 1999;33:372-379.

18. Hannig M, Balz M: Protective properties of salivary pellicles from two different intraoral sites on enamel erosion. Caries Research 2001;35:142-148.

19. Hannig C, Hamkens A, Becker K, Attin R, Attin T: Erosive effects of different acids on bovine enamel: release of calcium and phosphate in vitro. Arch Oral Biol 2005;50:541-552.

20. Meurman JH, Drysdale T, Frank RM: Experimental erosion of dentin. Scand J Dent Res 1991;99:457-462.

21. Eisenburger M, Shellis RP, Addy M: Scanning electron microscopy of softened enamel. Caries Res 2004;38:67-74.

22. Shellis RP, Hallsworth AS: The use of scanning electron microscopy in studying enamel caries. Scanning Microsc 
1987;1:1109-1123.

23. Barbour ME, Rees JS: The laboratory assessment of enamel erosion: a review. J Dent 2004;32:591-602.

24. Herkströter FM, Witjes M, Ruben J, Arends J: Time dependency of microhardness indentations in human and bovine dentine compared with human enamel. Caries Res 1989;23:342-344.

25. Lussi A, Jaeggi T, Jaeggi-Scharer S: Prediction of the erosive potential of some beverages. Caries Res 1995;29:349-354.

26. Featherstone JD, Ten C,J.M., Shariati M, Arends J: Comparison of artificial caries-like lesions by quantitative microradiography and microhardness profiles. Caries Res 1983;17:385-391.

27. Lussi A, Kohler N, Zero D, Schaffner M, Megert B: A comparison of the erosive potential of different beverages in primary and permanent teeth using an in vitro model. Eur J Oral Sci 2000;108:110-114.

28. Lussi A, Jaeggi T, Scharer S: The influence of different factors on in vitro enamel erosion. Caries Res 1993;27:387-393.

29. Lussi A, Jaeggi T, Zero D: The role of diet in the aetiology of dental erosion. Caries Res 2004;38:34-44.

30. Costa CC, Almeida IC, Costa Filho LC: Erosive effect of an antihistamine-containing syrup on primary enamel and its reduction by fluoride dentifrice. Int J Paediatr Dent 2006;16:174-180.

31. Jaeggi T, Lussi A: Toothbrush abrasion of erosively altered enamel after intraoral exposure to saliva: an in situ study. Caries Res 1999;33:455-461.

32. Joiner A, Weader E, Cox TF: The measurement of enamel wear of two toothpastes. Oral Health Prev Dent 2004;2:383-388. 
33. Joiner A, Schwarz A, Philpotts CJ, Cox TF, Huber K, Hannig M: The protective nature of pellicle towards toothpaste abrasion on enamel and dentine. J Dent 2008;36:360-368.

34. Voronets J, Lussi A: Thickness of softened human enamel removed by toothbrush abrasion: an in vitro study. Clin Oral Investig 2010;14:251-256.

35. Joiner A, Pickles MJ, Tanner C, Weader E, Doyle P: An in situ model to study the toothpaste abrasion of enamel. J Clin Periodontol 2004;31:434-438.

36. Lussi A, Jaeggi T, Gerber C, Megert B: Effect of amine/sodium fluoride rinsing on toothbrush abrasion of softened enamel in situ. Caries Res 2004;38:567-571.

37. Schweizer-Hirt CM, Schait A, Schmid R, Imfeld T, Lutz F, Muhlemann HR: [Erosion and abrasion of the dental enamel. Experimental study]. SSO Schweiz Monatsschr Zahnheilkd 1978;88:497-529.

38. Hooper S, West NX, Sharif N, Smith S, North M, De'Ath J, Parker DM, Roedig-Penman A, Addy M: A comparison of enamel erosion by a new sports drink compared to two proprietary products: a controlled, crossover study in situ. J Dent 2004;32:541-545.

39. Ganss C, Klimek J, Schwarz N: A comparative profilometric in vitro study of the susceptibility of polished and natural human enamel and dentine surfaces to erosive demineralization. Arch Oral Biol 2000;45:897-902.

40. Cochrane NJ, Cai F, Yuan Y, Reynolds EC: Erosive potential of beverages sold in Australian schools. Aust Dent J 2009;54:238-44; quiz 277.

41. Cochrane NJ, Yuan Y, Walker GD, Shen P, Chang CH, Reynolds C, Reynolds EC: Erosive potential of sports beverages. Aust Dent J 
2012;57:359-64; quiz 398.

42. Ablal MA, Kaur JS, Cooper L, Jarad FD, Milosevic A, Higham SM, Preston AJ: The erosive potential of some alcopops using bovine enamel: an in vitro study. J Dent 2009;37:835-839.

43. Eisenburger M: Degree of mineral loss in softened human enamel after acid erosion measured by chemical analysis. J Dent 2009;37:491-494.

44. Chuenarrom C, Benjakul P: Dental erosion protection by fermented shrimp paste in acidic food. Caries Res 2010;44:20-23.

45. Chunmuang S, Jitpukdeebodintra S, Chuenarrom C, Benjakul P: Effect of xylitol and fluoride on enamel erosion in vitro. J Oral Sci 2008;49:293-297.

46. Caglar E, Cildir SK, Sandalli N: The erosive potential of different malt drinks: an in vitro and in situ study. J Clin Pediatr Dent 2008;33:35-37.

47. Engle K, Hara AT, Matis B, Eckert GJ, Zero DT: Erosion and abrasion of enamel and dentin associated with at-home bleaching: an in vitro study. J Am Dent Assoc 2010;141:546-551.

48. Hughes JA, Jandt KD, Baker N, Parker D, Newcombe RG, Eisenburger M, Addy M: Further modification to soft drinks to minimise erosion. A study in situ. Caries Res 2002;36:70-74.

49. West NX, Hughes JA, Parker DM, Moohan M, Addy M: Development of low erosive carbonated fruit drinks 2. Evaluation of an experimental carbonated blackcurrant drink compared to a conventional carbonated drink. J Dent 2003;31:361-365.

50. Beyer M, Reichert J, Sigusch BW, Watts DC, Jandt KD: Morphology and structure of polymer layers protecting dental enamel against erosion. Dent Mater 2012;28:1089-1097. 
51. Beyer M, Reichert J, Bossert J, Sigusch BW, Watts DC, Jandt KD: Acids with an equivalent taste lead to different erosion of human dental enamel. Dent Mater 2011;27:1017-1023.

52. Whitehead SA, Shearer AC, Watts DC, Wilson NHF: Comparison of two stylus methods for measuring surface texture. Dent Mater 1999;15:79-86.

53. Hooper S, West NX, Pickles MJ, Joiner A, Newcombe RG, Addy $\mathrm{M}$ : Investigation of erosion and abrasion on enamel and dentine: a model in situ using toothpastes of different abrasivity. J Clin Periodontol 2003;30:802-808.

54. Venables MC, Shaw L, Jeukendrup AE, Roedig-Penman A, Finke M, Newcombe RG, Parry J, Smith AJ: Erosive effect of a new sports drink on dental enamel during exercise. Med Sci Sports Exerc 2005;37:39-44.

55. Attin T, Weiss K, Becker K, Buchalla W, Wiegand A: Impact of modified acidic soft drinks on enamel erosion. Oral Dis 2005;11:712.

56. Attin T, Becker K, Roos M, Attin R, Paque F: Impact of storage conditions on profilometry of eroded dental hard tissue. Clin Oral Investig 2009;13:473-478.

57. Ganss C, Hardt M, Blazek D, Klimek J, Schlueter N: Effects of toothbrushing force on the mineral content and demineralized organic matrix of eroded dentine. Eur J Oral Sci 2009;117:255-260.

58. Chadwick RG, Mitchell HL, Cameron I, Hunter B, Tulley M: Development of a novel system for assessing tooth and restoration wear. J Dent 1997;25:41-47.

59. Mitchell HL, Chadwick RG, Ward S, Manton SL: Assessment of a procedure for detecting minute levels of tooth erosion. Med Biol Eng Comput 2003;41:464-469. 
60. Mitchell HL, Chadwick RG: Mathematical shape matching as a tool in tooth wear assessment--development and conduct. J Oral Rehabil 1998;25:921-928.

61. Chadwick RG, Mitchell HL, Ward S: Evaluation of the accuracy and reproducibility of a replication technique for the manufacture of electroconductive replicas for use in quantitative clinical dental wear studies. J Oral Rehabil 2002;29:540-545.

62. Chadwick RG, Mitchell HL, Ward S: A novel approach to evaluating the reproducibility of a replication technique for the manufacture of electroconductive replicas for use in quantitative clinical dental wear studies. J Oral Rehabil 2004;31:335-339.

63. Bakhos Y, Brudevold F, Aasenden R: In-vivo estimation of the permeability of surface human enamel. Arch Oral Biol 1977;22:599-603.

64. Brudevold F, Tehrani A, Cruz R: The relationship among the permeability to iodide, pore volume, and intraoral mineralization of abraded enamel. J Dent Res 1982;61:645-648.

65. Bakhos Y, Brudevold F: Effect of initial demineralization on the permeability of human tooth enamel to iodide. Arch Oral Biol 1982;27:193-196.

66. Zero DT, Rahbek I, Fu J, Proskin HM, Featherstone JD: Comparison of the iodide permeability test, the surface microhardness test, and mineral dissolution of bovine enamel following acid challenge. Caries Res 1990;24:181-188.

67. Ten Cate JM, Larsen MJ, Pearce EI, Fejerskov O 2003. Chemical interactions between the tooth and oral fluids. In Dental Caries. The disease and its management, eds. Fejerskov O, Kidd EAM, pp. 49-70. Copenhagen: Blackwell Munksgaard

68. Hannig M, Hess NJ, Hoth-Hannig W, De V,M.: Influence of 
salivary pellicle formation time on enamel demineralization--an in situ pilot study. Clin Oral Investig 2003;7:158-161.

69. van Rijkom H, Ruben J, Vieira A, Huysmans MC, Truin GJ, Mulder J: Erosion-inhibiting effect of sodium fluoride and titanium tetrafluoride treatment in vitro. Eur J Oral Sci 2003;111:253-257.

70. Nekrashevych Y, Stosser L: Protective influence of experimentally formed salivary pellicle on enamel erosion. An in vitro study. Caries Res 2003;37:225-231.

71. Mahoney E, Beattie J, Swain M, Kilpatrick N: Preliminary in vitro assessment of erosive potential using the ultra-micro-indentation system. Caries Res 2003;37:218-224.

72. Grenby TH, Phillips A, Desai T, Mistry M: Laboratory studies of the dental properties of soft drinks. Brit J Nutr 1989;62:451-464.

73. Wegehaupt FJ, Sener B, Attin T, Schmidlin PR: Anti-erosive potential of amine fluoride, cerium chloride and laser irradiation application on dentine. Arch Oral Biol 2011;56:1541-1547.

74. Borjian A, Ferrari CC, Anouf A, Touyz LZ: Pop-cola acids and tooth erosion: an in vitro, in vivo, electron-microscopic, and clinical report. Int J Dent 2010;2010:957842.

75. Caglar E, Lussi A, Kargul B, Ugur K: Fruit yogurt: any erosive potential regarding teeth? Quintessence Int 2006;37:647-651.

76. Al-Salehi SK, Wood DJ, Hatton PV: The effect of 24h non-stop hydrogen peroxide concentration on bovine enamel and dentine mineral content and microhardness. J Dent 2007;35:845-850.

77. Chen PS, Toribara TY, Warner H: Microdetermination of Phosphorus. Anal Chem 1956;28:1756-1758.

78. Lowry OH, Roberts NR, Leiner KJ, Wu ML, Farr L: The quantitative histochemistry of the brain. J Biol Chem 1954;207:1- 
15.

79. Hohenwallner W, Wimmer E: Malachite green micromethod for determination of inorganic-phosphate. Clin Chim Acta 1973;45:169-175.

80. Hattab F, Linden LA: Micro-determination of phosphate in enamel biopsy samples using the malachite green method. Acta Odontol Scand 1984;42:85-91.

81. Attin T, Becker K, Hannig C, Buchalla W, Wiegand A: Suitability of a malachite green procedure to detect minimal amounts of phosphate dissolved in acidic solutions. Clin Oral Investig 2005;9:203-207.

82. de Josselin de J,E., van der L,A.H., ten B,J.J.: Longitudinal microradiography: a non-destructive automated quantitative method to follow mineral changes in mineralised tissue slices. Phys Med Biol 1987;32:1209-1220.

83. de Josselin de J,E., van der L,A.H., Borsboom PC, ten B,J.J.: Determination of mineral changes in human dental enamel by longitudinal microradiography and scanning optical monitoring and their correlation with chemical analysis. Caries Res 1988;22:153159.

84. Anderson P, Elliott JC: Rates of mineral loss in human enamel during in vitro demineralization perpendicular and parallel to the natural surface. Caries Res 2000;34:33-40.

85. Fejerskov O, Nyvad B, Kidd EAM 2003. Clinical and histological manifestations of dental caries. In Dental Caries. The disease and its clinical management., eds. Fejerskov O, Kidd EAM, pp. 71-98. Oxford: Blackwell Munksgaard

86. Hall AF, Sadler JP, Strang R, de Josselin de J,E., Foye RH, Creanor SL: Application of transverse microradiography for 
measurement of mineral loss by acid erosion. Adv Dent Res 1997;11:420-425.

87. Amaechi BT, Higham SM, Edgar WM: Use of transverse microradiography to quantify mineral loss by erosion in bovine enamel. Caries Res 1998;32:351-356.

88. Mathews MS, Amaechi BT, Ramalingam K, Ccahuana-Vasquez RA, Chedjieu IP, Mackey AC, Karlinsey RL: In situ remineralisation of eroded enamel lesions by $\mathrm{NaF}$ rinses. Arch Oral Biol 2012;57:525-530.

89. Amaechi BT, Higham SM: In vitro remineralisation of eroded enamel lesions by saliva. J Dent 2001;29:371-376.

90. Amaechi BT, Higham SM: Eroded enamel lesion remineralization by saliva as a possible factor in the site-specificity of human dental erosion. Arch Oral Biol 2001;46:697-703.

91. Ganss C, Klimek J, Schaffer U, Spall T: Effectiveness of two fluoridation measures on erosion progression in human enamel and dentine in vitro. Caries Res 2001;35:325-330.

92. Ganss C, Klimek J, Brune V, Schurmann A: Effects of two fluoridation measures on erosion progression in human enamel and dentine in situ. Caries Res 2004;38:561-566.

93. Ganss C, Klimek J, Starck C: Quantitative analysis of the impact of the organic matrix on the fluoride effect on erosion progression in human dentine using longitudinal microradiography. Arch Oral Biol 2004;49:931-935.

94. Buchalla W, Imfeld T, Attin T, Swain MV, Schmidlin PR:

Relationship between nanohardness and mineral content of artificial carious enamel lesions. Caries Res 2008;42:157-163.

95. Ganss C, Lussi A, Klimek J: Comparison of calcium/phosphorus analysis, longitudinal microradiography and profilometry for the 
quantitative assessment of erosive demineralisation. Caries Res 2005;39:178-184.

96. Duschner H, Sõnju-Clasen B, Øgaard B 1996. Detection of early caries by confocal laser scanning microscopy. In Early detecion of dental caries, ed. Stookey GK, pp. 145-156. Indianapolis, Indiana: Indiana University Press

97. Grotz KA, Duschner H, Reichert TE, de A,E.G., Gîtz H, Wagner W: Histotomography of the odontoblast processes at the dentineenamel junction of permanent healthy human teeth in the confocal laser scanning microscope. Clin Oral Investig 1998;2:21-25.

98. White DJ, Kozak KM, Zoladz JR, Duschner H, Gotz H: Peroxide interactions with hard tissues: effects on surface hardness and surface/subsurface ultrastructural properties. Compend Contin Educ Dent 2002;23:42-48.

99. Duschner H, Gîtz H, Walker H, Lussi A 2000. Erosion of dental enamel visualized by confocal laser scanning microscopy. In Tooth wear and sensitivity, eds. Addy M, Embery G, Edgar WM, Orchadson R, pp. 67-73. London: Martin Dunitz

100. Lussi A, Hellwig E: Erosive potential of oral care products. Caries Research 2001;35 Suppl 1:52-56.

101. Zentner A, Duschner H: Structural changes of acid etched enamel examined under confocal laser scanning microscope. J Orofac Orthop 1996;57:202-209.

102. Min JH, Kwon HK, Kim BI: The addition of nano-sized hydroxyapatite to a sports drink to inhibit dental erosion: in vitro study using bovine enamel. J Dent 2011;39:629-635.

103. van der Veen MH, de Josselin de Jong E 2000. Application of quantitative light-induced fluorescence for assessing early caries lesions. In Assessment of oral health: Diagnostic techniques and 
validation criteria, ed. Faller RV, pp. 144-162. Basel: Karger

104. Pretty IA, Edgar WM, Higham SM: The erosive potential of commercially available mouthrinses on enamel as measured by Quantitative Light-induced Fluorescence (QLF). J Dent 2003;31:313-319.

105. Pretty IA, Edgar WM, Higham SM: The validation of quantitative light-induced fluorescence to quantify acid erosion of human enamel. Arch Oral Biol 2004;49:285-294.

106. Elton V, Cooper L, Higham SM, Pender N: Validation of enamel erosion in vitro. J Dent 2009;37:336-341.

107. Jandt KD: Atomic force microscopy of biomaterials surfaces and interfaces. Surf Sci 2001;491:303-332.

108. Lippert F, Parker DM, Jandt KD: In vitro demineralization/remineralization cycles at human tooth enamel surfaces investigated by AFM and nanoindentation. J Colloid Interface Sci 2004;280:442-448.

109. Lippert F, Parker DM, Jandt KD: Toothbrush abrasion of surface softened enamel studied with tapping mode AFM and AFM nanoindentation. Caries Res 2004;38:464-472.

110. Finke M, Jandt KD, Parker DM: The early stages of native enamel dissolution studied with atomic force microscopy. Journal Colloid Interface Sci 2000;232:156-164.

111. Poggio C, Lombardini M, Vigorelli P, Colombo M, Chiesa M: The role of different toothpastes on preventing dentin erosion: An SEM and AFM study(R). Scanning 2013

112. Cross SE, Kreth J, Wali RP, Sullivan R, Shi W, Gimzewski JK: Evaluation of bacteria-induced enamel demineralization using optical profilometry. Dent Mater 2009;25:1517-1526. 
113. Oliver WC, Pharr GM: An Improved Technique for Determining Hardness and Elastic-Modulus Using Load and Displacement

Sensing Indentation Experiments. J Mater Res 1992;7:1564-1583.

114. Abdullah AZ, Ireland AJ, Sandy JR, Barbour ME: A

Nanomechanical Investigation of Three Putative Anti-Erosion Agents: Remineralisation and Protection against Demineralisation. Int J Dent 2012;2012:768126.

115. Finke M, Hughes JA, Parker DM, Jandt KD: Mechanical properties of in situ demineralised human enamel measured by AFM nanoindentation. Surf Sci 2001;491:456-467.

116. Barbour ME, Finke M, Parker DM, Hughes JA, Allen GC, Addy $\mathrm{M}$ : The relationship between enamel softening and erosion caused by soft drinks at a range of temperatures. J Dent 2006;34:207-213.

117. Lodding AR, Fischer PM, Odelius H, Noren JG, Sennerby L, Johansson CB, Chabala JM, Levisetti R: Secondary Ion MassSpectrometry in the Study of Biomineralizations and Biomaterials. Anal Chim Acta 1990;241:299-314.

118. Becker JS, Dietze HJ: Inorganic trace analysis by mass spectrometry. Spectrochim Acta [B] 1998;53:1475-1506.

119. Love G, Scott VD: Electron probe microanalysis using soft X-rays - a review. part 1: Instrumentation, spectrum processing and detection sensitivity. J Microsc (Oxf) 2001;201:1-32.

120. Willershausen B, Schulz-Dobrick B: In vitro study on dental erosion provoked by various beverages using electron probe microanalysis. Eur J Med Res 2004;9:432-438.

121. Huysmans MC, Thijssen JM: Ultrasonic measurement of enamel thickness: a tool for monitoring dental erosion? J Dent 2000;28:187-191.

122. Louwerse C, Kjaeldgaard M, Huysmans MC: The reproducibility Attin 
of ultrasonic enamel thickness measurements: an in vitro study. $\mathrm{J}$ Dent 2004;32:83-89.

123. Arslantunali T, D., Ozturk F, Lagerweij M, Hayran O, Stookey GK, Caliskan Y, F.: Thickness measurement of worn molar cusps by ultrasound. Caries Res 2005;39:139-143. 


\begin{tabular}{|c|c|c|c|c|}
\hline Method & Advantages & Problems & $\begin{array}{l}\text { Suitability } \\
\text { for early } \\
\text { erosion }\end{array}$ & $\begin{array}{l}\text { Suitability } \\
\text { for use } \\
\text { with native } \\
\text { surfaces }\end{array}$ \\
\hline $\begin{array}{l}\text { Scanning Electron Microscopy } \\
\text { (SEM) and Enviromental SEM }\end{array}$ & $\begin{array}{l}\text { - Applicable for wet samples } \\
\text { (ESEM) }\end{array}$ & - Only qualitative assessment & + & ++ \\
\hline Surface hardness measurements & $\begin{array}{l}\text { - Relatively low costs } \\
\text { - Long experience } \\
\text { - Not time-consuming } \\
\text { - Can be combined with } \\
\text { determination of surface loss due } \\
\text { to abrasion }\end{array}$ & $\begin{array}{l}\text { - Measurement of surface hardness is } \\
\text { influenced by non-demineralized } \\
\text { deeper layers } \\
\text { - Polished, flat surfaces needed }\end{array}$ & ++ & - \\
\hline Surface Profilometry & $\begin{array}{l}\text { Applicable for measurement in } \\
\text { natural dentition (replica } \\
\text { technique) }\end{array}$ & $\begin{array}{l}\text { - } \text { Time-consuming when complete } \\
\text { mapping of surfaces } \\
\text { - } \text { Stylus could damage surface } \\
\end{array}$ & $-/+$ & $-/+$ \\
\hline $\begin{array}{l}\text { Surface } 3 \mathrm{D} \text { focus-variation scanning } \\
\text { microscopy }\end{array}$ & 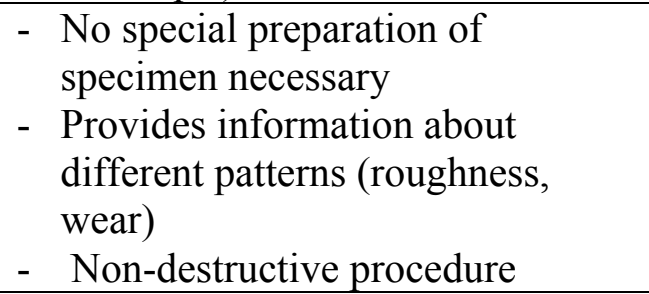 & $\begin{array}{ll}\text { - } & \text { Time consuming } \\
\text { - } & \text { Repetitive measurements of } \\
\text { identical regions are difficult }\end{array}$ & $-/+$ & $-/+$ \\
\hline Iodide permeability test & - Low costs & $\begin{array}{l}\text { - Provides only information about } \\
\text { increased pore volumes }\end{array}$ & $-/+$ & + \\
\hline $\begin{array}{l}\text { Attenuated Total Reflectance Infrared } \\
\text { Spectroscopy }\end{array}$ & $\begin{array}{l}\text { - Determination of mineral changes } \\
\text { throuphout athe complte surface } \\
\text { ayer is possible }\end{array}$ & $\begin{array}{ll}\text { - } & \text { Sample preparation is demanding } \\
\text { - } & \text { Limited quantification of erosive } \\
\text { damage }\end{array}$ & + & - \\
\hline $\begin{array}{l}\text { Chemical analysis of dissolved } \\
\text { minerals }\end{array}$ & $\begin{array}{l}\text { - Mostly easy and well-established } \\
\text { methods }\end{array}$ & $\begin{array}{l}\text { - No information about structural } \\
\text { changes }\end{array}$ & +++ & +++ \\
\hline Microradiography & $\begin{array}{l}\text { - Determination of both mineral } \\
\text { loss and demineralization possible }\end{array}$ & $\begin{array}{l}\text { - Limited resolution } \\
\text { - Demanding sample preparation }\end{array}$ & - & - \\
\hline Confocal laser scanning microscopy & - High resolution & - Only qualitative assessment & ++ & $-1+$ \\
\hline Quantitative light-induced & - Surface scan is not time- & - Limited resolution & - & - \\
\hline
\end{tabular}




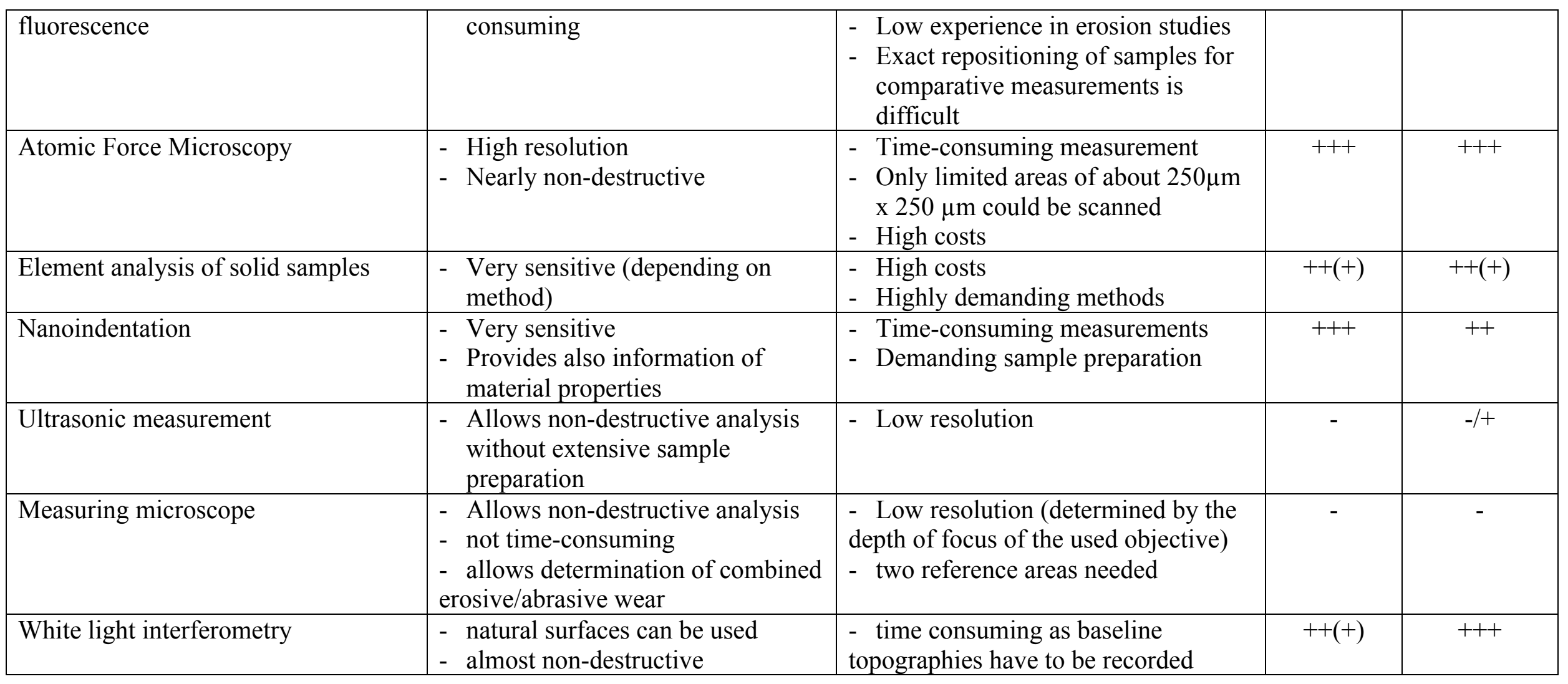

Table 1: Survey of the methods described in detail in the text with respect to main advantages and problems as well as to suitability for use with early erosions (after few minutes of acidic challenge) and with native, non-polished surface samples.

$$
\begin{aligned}
& +++=\text { highly suitable } \\
& ++=\text { very suitable } \\
& +\quad=\text { suitable } \\
& -/+\quad=\text { limitedly suitable } \\
& -\quad=\text { not suitable }
\end{aligned}
$$

